\section{Acknowledgments}

This work was supported by the Rosalind Russell Medical Research Foundation Bechtel Award (to J. Zikherman), Arthritis National Research Foundation (to J. Zikherman), and NIH K08 AR059723 (to J. Zikherman).

Address correspondence to: Arthur Weiss, 513 Parnassus Avenue, Room S-1032C, Box 0795, San Francisco, California 941430795, USA. Phone: 415.476.1291; Fax: 415.502.5081; E-mail: aweiss@medicine. ucsf.edu.

1. Wellcome Trust Case Control Consortium Genome-wide association study of 14,000 cases of seven common diseases and 3,000 shared controls. Nature. 2007;447(7145):661-678.

2. Doody KM, Bourdeau A, Tremblay ML. T-cell protein tyrosine phosphatase is a key regulator in immune cell signaling: lessons from the knockout mouse model and implications in human disease. Immunol Rev. 2009;228(1):325-341.

3 . Todd JA, et al. Robust associations of four new chromosome regions from genome-wide analyses of type 1 diabetes. Nat Genet. 2007;39(7):857-864.

4. Wiede F, et al. T cell protein tyrosine phosphatase attenuates $\mathrm{T}$ cell signaling to maintain tolerance in mice. J Clin Invest. 2011;121(12):4758-4774.

5 . You-Ten KE, et al. Impaired bone marrow microenvironment and immune function in $\mathrm{T}$ cell protein tyrosine phosphatase-deficient mice. J Exp Med. 1997;186(5):683-693.
6. Heinonen KM, et al. T-cell protein tyrosine phosphatase deletion results in progressive systemic inflammatory disease. Blood. 2004; 103(9):3457-3464.

7. Simoncic PD, Lee-Loy A, Barber DL, Tremblay ML, McGlade CJ. The T cell protein tyrosine phosphatase is a negative regulator of janus family kinases 1 and 3. Curr Biol. 2002;12(6):446-453.

8. Aoki N, Matsuda T. A nuclear protein tyrosine phosphatase TC-PTP is a potential negative regulator of the PRL-mediated signaling pathway: dephosphorylation and deactivation of signal transducer and activator of transcription 5a and 5 b by TC-PTP in nucleus. Mol Endocrinol. 2002; 16(1):58-69.

9. van Vliet C, et al. Selective regulation of tumor necrosis factor-induced Erk signaling by Src family kinases and the $\mathrm{T}$ cell protein tyrosine phosphatase. Nat Immunol. 2005;6(3):253-260.

10. Long SA, et al. An autoimmune-associated variant in PTPN2 reveals an impairment of IL-2R signaling in CD4(+) T cells. Genes Immun. 2011;12(2):116-125.

11. Hassan SW, Doody KM, Hardy S, Uetani N, Cournoyer D, Tremblay ML. Increased susceptibility to dextran sulfate sodium induced colitis in the T cell protein tyrosine phosphatase heterozygous mouse. PLoS One. 2010;5(1):e8868.

12. Hermiston ML, Zikherman J, Zhu JW. CD45 CD148, and Lyp/Pep: critical phosphatases regulating Src family kinase signaling networks in immune cells. Immunol Rev. 2009;228(1):288-311.

13. Zikherman J, Weiss A. Antigen receptor signaling in the rheumatic diseases. Arthritis Res Ther. 2009;11(1):202.

14. Bottini $\mathrm{N}$, et al. A functional variant of lymphoid tyrosine phosphatase is associated with type I diabetes. Nat Genet. 2004;36(4):337-338.

15. Kyogoku C, et al. Genetic association of the R620W polymorphism of protein tyrosine phosphatase
PTPN22 with human SLE. Am J Hum Genet. 2004;75(3):504-507

16. Begovich $\mathrm{AB}$, et al. A missense single-nucleotide polymorphism in a gene encoding a protein tyrosine phosphatase (PTPN22) is associated with rheumatoid arthritis. Am J Hum Genet. 2004;75(2):330-337.

17. Cloutier JF, Veillette A. Cooperative inhibition of T-cell antigen receptor signaling by a complex between a kinase and a phosphatase. J Exp Med. 1999;189(1):111-121.

18. Hasegawa K, Martin F, Huang G, Tumas D, Diehl L, Chan AC. PEST domain-enriched tyrosine phosphatase (PEP) regulation of effector/memory T cells. Science. 2004;303(5658):685-689.

19. Vang T, et al. Autoimmune-associated lymphoid tyrosine phosphatase is a gain-of-function variant. Nat Genet. 2005;37(12):1317-1319.

20. Zikherman J, Hermiston M, Steiner D, Hasegawa $\mathrm{K}$, Chan A, Weiss A. PTPN22 deficiency cooperates with the CD45 E613R allele to break tolerance on a non-autoimmune background. J Immunol. 2009;182(7):4093-4106.

21. Arechiga AF, et al. Cutting edge: the PTPN22 allelic variant associated with autoimmunity impairs $B$ cell signaling. J Immunol. 2009;182(6):3343-3347.

22. Rieck M, Arechiga A, Onengut-Gumuscu S, Greenbaum C, Concannon P, Buckner JH. Genetic variation in PTPN22 corresponds to altered function of T and B lymphocytes. J Immunol. 2007;179(7):4704-4710.

23. Zhang J, et al. The autoimmune disease-associated PTPN22 variant promotes calpain-mediated Lyp/Pep degradation associated with lymphocyte and dendritic cell hyperresponsiveness. Nat Genet. 2011;43(9):902-907.

24. Diaz-Gallo LM, et al. Differential association of two PTPN22 coding variants with Crohn's disease and ulcerative colitis [published online ahead of print February 1, 2011]. Inflamm Bowel Dis. doi:10.1002/ibd.21630.

\title{
A new medical therapy for Cushing disease?
}

\section{Fredric E. Wondisford}

Department of Pediatrics, Department of Medicine, and Department of Physiology, Johns Hopkins University School of Medicine, Baltimore, Maryland, USA.

\begin{abstract}
Members of the ErbB family of cell surface tyrosine kinase receptors are important targets for cancer treatment because they frequently contribute to the pathogenesis of malignancy. In this issue of the JCI, Fukuoka et al. generate data that suggest that using a tyrosine kinase inhibitor (TKI) against epidermal growth factor receptor (EGFR; also known as ErbB1) may be a novel approach for treating patients with hypercortisolemia due to pituitary corticotroph adenomas (Cushing disease). While surgical resection remains the cornerstone of treatment for individuals with such tumors, this study suggests that TKIs could perhaps be used to reduce tumor size prior to surgery or to treat recurrent disease after surgery.
\end{abstract}

Cushing disease is a condition in which the pituitary gland releases too much adrenocorticotropic hormone (ACTH), the hormone that stimulates the secretion of cortisol from the adrenal cortex (Figure 1 and ref. 1). Cor-

Conflict of interest: The author has declared that no conflict of interest exists.

Citation for this article: J Clin Invest. 2011; 121(12):4621-4623. doi:10.1172/JCI61127. tisol, which is normally released in response to stress or reduced levels of serum glucocorticoids, regulates blood glucose levels by promoting gluconeogenesis, suppresses the immune system, and accelerates protein metabolism. Hypercortisolemia is the hallmark of Cushing disease and causes a diverse array of symptoms, including central obesity, hypertension, hyperglycemia, osteoporosis, and skin and muscle atrophy.
Cushing disease is caused by an adenoma arising from pituitary corticotroph cells. These cells, which are found in the anterior pituitary, produce ACTH from the precursor proopiomelanocortin (POMC) and then secrete it in response to corticotropin-releasing hormone from the hypothalamus (Figure 1). Treatment options for patients with Cushing disease are essentially limited to surgical resection. However, surgical resection alone has several important limitations (reviewed in ref. 1). First, preoperative studies to localize the tumor are not always definitive, since the majority of pituitary corticotroph adenomas are very small in size (less than $10 \mathrm{~mm}$ in diameter). Second, surgical remission rates for larger tumors are relatively low. Finally, postoperative recurrence rates range from $10 \%$ to $45 \%$, depending on the size of the initial tumor. 


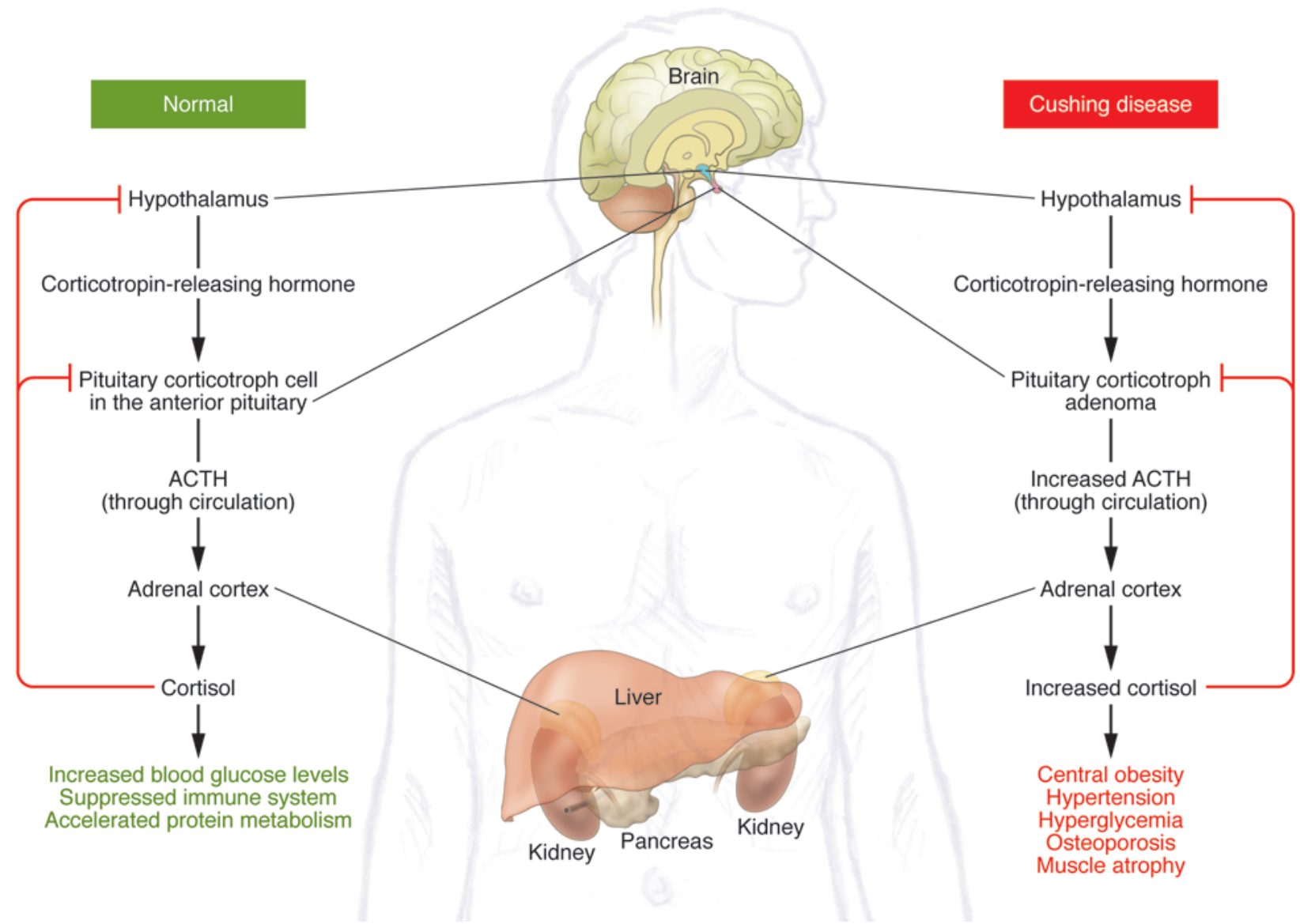

Figure 1

The hypothalamic-pituitary-adrenal (HPA) axis in healthy controls and patients with Cushing disease. The normal HPA axis is subject to negative feedback regulation by circulating cortisol levels. Cortisol normally regulates carbohydrate, protein, and lipid metabolism and plays a key role in the immune system. In Cushing disease, a pituitary corticotroph adenoma secreting too much ACTH activates the HPA axis, resulting in defective negative feedback and excessive cortisol production. Patients exhibit central obesity, hypertension, hyperglycemia, osteoporosis, and muscle atrophy.

Given the limitations of surgical resection, new medical treatment options are needed for patients with Cushing disease. Clinical trials with a dopamine agonist (2) and a somatostatin analog (3) - which work by limiting tumor secretion of ACTH and subsequent hypercortisolism - have shown some promise, but only

\section{Figure 2}

Proposed function of the EGFR in pituitary corticotrophs. (A) Relationship between Pomc expression (which encodes a precursor protein that can be cleaved to generate $\mathrm{ACTH}$ ) and pituitary cell growth mediated by the MAPK pathway. Corticotroph adenomas have aberrant MAPK pathway activation, resulting in pituitary cell growth and increased Pomc expression (4). (B) Use of a TKI reduces corticotroph adenoma growth and Pomc expression, which is mediated by the MAPK signaling pathway. in a small proportion of patients. In this issue of the JCI, Fukuoka et al. report data that suggest that targeting the ErbB family member EGFR (also known as ErbB1) could provide a pituitary-targeted medical treatment option prior to or after surgical resection of a pituitary corticotroph adenoma (4).

\section{A}

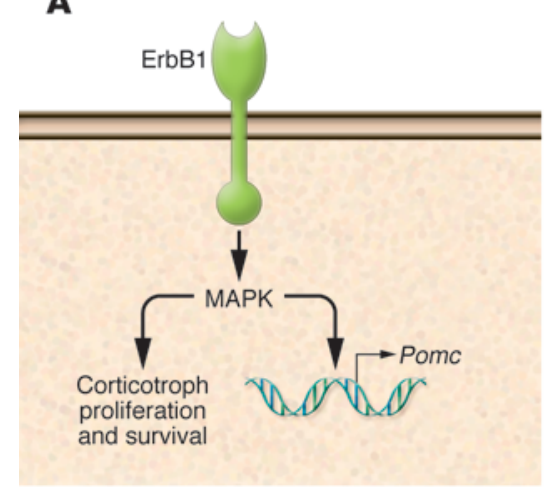

\section{Mutations in EGFR in cancer}

Members of the ErbB family are mutated or overexpressed in a variety of human solid tumors, and this has been show to play an important role in the pathogenesis of these malignancies (5). The intrinsic tyrosine kinase activity of EGFR and ErbB2 is aug-

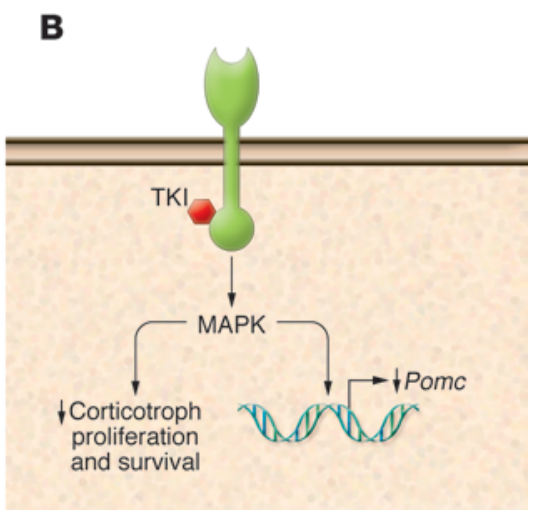


mented by overexpression or by mutation in many human tumors, and this facilitates tumor growth. Targeting these receptors has therefore been intensively pursued as an important anticancer therapeutic strategy.

Tyrosine kinase inhibitors (TKIs) such as gefitinib and erlotinib have been developed against EGFR, and they block receptor activity by inhibiting ATP binding to the kinase site. Gefitinib and erlotinib are somewhat effective in the treatment of non-small cell lung cancers that have activating mutations in the kinase domain of EGFR. However, many patients who are initially responsive to these therapeutics subsequently experience tumor recurrence and become refractory to therapy (6).

\section{EGFR and ACTH expression}

Although a substantial proportion of pituitary corticotroph adenomas have been shown to express EGFR (7-9), the role of this receptor in the pathogenesis of Cushing disease has not been determined. Fukuoda et al. set out to test the hypothesis that EGFR activation is important in the pathogenesis of pituitary corticotroph adenomas and that gefitinib could inhibit both EGFR activation and tumor growth (4). Remarkably, they showed that gefitinib substantially reduced $P O M C$ mRNA expression and ACTH secretion in cell lines derived from human, canine, and mouse pituitary corticotroph adenomas. They further showed that changes at the proximal mouse Pomc promoter mediated this effect in in vitro transfection studies and that the effect of EGF on the Pomc promoter was MAPK dependent (Figure 2A).

The ability of gefitinib to suppress Pomc mRNA levels in mouse corticotroph cell cultures correlated directly with an increase in markers of apoptosis and a decrease in cellular proliferation (4). Furthermore, gefitinib also decreased tumor growth and serum ACTH levels in mice allografted with an EGFR-overexpressing mouse corticotroph tumor cell line. The authors therefore concluded that gefitinib is useful in reducing ACTH levels as well as corticotroph cell growth, both in vitro and in vivo. As a result, they suggest a role for TKIs in the treatment of patients with Cushing disease.

\section{A new therapy for Cushing disease?}

The work of Fukuoda et al. (4) provides the rationale for a potential new medical treatment option for patients with Cushing disease - using a TKI such as gefitinib prior to surgery, to increase the chance that a large pituitary corticotroph adenoma can be successfully resected, or after surgery, to reduce postoperative recurrence rates (Figure $2 \mathrm{~B}$ ). However, the authors note two limitations to using TKIs for treating patients with Cushing disease (4). First, not all pituitary corticotroph adenomas express EGFR, and those that do not would not be affected by gefitinib. This was evidenced by the authors' results with their canine model of Cushing disease, in which a few animals were found to be unresponsive to gefitinib because they lacked EGFR expression in their pituitary tumor (4). Second, gefitinib is particularly effective in the clinical setting of tumors bearing the EGFR L858R mutation, which is found in many patients with non-small cell lung cancer (10). Fukuoka et al. point out that it is not clear whether human pituitary corticotroph adenomas harbor this mutation. Other limitations of the strategy come to mind; for example, the effect of gefitinib on ACTH secretion might be dissociated from its effect on tumor cell growth, rendering it less useful for long-term treatment of Cushing disease. Moreover, pituitary corticotroph adenomas treated with gefitinib may develop resistance to the drug by acquiring new mutations in the EGF signaling pathway or by activating signaling from a related family member, such as ErbB3. As noted above, use of this drug in individuals with non-small cell lung cancer suggests that resistance could become a concern (6).

\section{Conclusions}

Regardless of the potential clinical limitations, the work of Fukuoka et al. provides a novel candidate approach for treating patients with Cushing disease based on solid mechanistic science (4). It highlights a previously underappreciated pathway regulating Pomc expression (7-9) and provides a rational approach to regulating this pathway in the clinic. More needs to be learned about the effects of TKIs on human pituitary corticotroph adenomas, especially the ability of such drugs to affect tumor cell growth and tumor survival. However, this study provides a strong foundation to investigate the effects of gefitinib in patients with Cushing disease. Physicians caring for these patients will anxiously await the results.

\section{Acknowledgments}

The author's work is supported by NIH funding for the Baltimore Diabetes Research and Training Center (P60 DK79637) and by NIH grants R01DK63349 and R01DK49126.

Address correspondence to: Fredric E. Wondisford, JHU-UMD Diabetes Research and Training Center, Johns Hopkins University School of Medicine, 600 N. Wolfe Street, CMSC10-113, Baltimore, Maryland 21287, USA. Phone: 410.502.5761; Fax: 410.502.5779; E-mail: fwondisford@jhmi.edu.

1. Tritos NA, Biller BM, Swearingen B. Management of Cushing disease. Nat Rev Endocrinol. 2011;7(5):279-289.

2. Pivonello R, et al. The medical treatment of Cushing's disease: effectiveness of chronic treatment with the dopamine agonist cabergoline in patients unsuccessfully treated by surgery. J Clin Endocrinol Metab. 2009;94(1):223-230.

3. Boscaro M, et al. Treatment of pituitary-dependent Cushing's disease with the multireceptor ligand somatostatin analog pasireotide (SOM230): a multicenter, phase II trial. J Clin Endocrinol Metab. 2009;94(1):115-122.

4. Fukuoka $\mathrm{H}$, et al. EGFR as a therapeutic target for human, canine, and mouse ACTH-secreting pituitary adenomas. J Clin Invest. 2011;121(12):4712-4721.

5. Zhang H, et al. ErbB receptors: from oncogenes to targeted cancer therapies. J Clin Invest. 2007;117(8):2051-2058.

6. Wang Q, Greene MI. Mechanisms of resistance to ErbB-targeted cancer therapeutics. J Clin Invest. 2008;118(7):2389-2392.

7. LeRiche VK, Asa SL, Ezzat S. Epidermal growth factor and its receptor (EGF-R) in human pituitary adenomas: EGF-R correlates with tumor aggressiveness. J Clin Endocrinol Metab. 1996;81(2):656-662.

8. Onguru $\mathrm{O}$, et al. Analysis of epidermal growth factor receptor and activated epidermal growth factor receptor expression in pituitary adenomas and carcinomas. Mod Pathol. 2004;17(7):772-780.

9. Theodoropoulou M, et al. Expression of epidermal growth factor receptor in neoplastic pituitary cells: evidence for a role in corticotropinoma cells. J Endocrinol. 2004;183(2):385-394.

10. Paez JG, et al. EGFR mutations in lung cancer: correlation with clinical response to gefitinib therapy. Science. 2004;304(5676):1497-1500. 